\title{
Energy savings in HVAC systems by continuous monitoring. Results of a long term monitoring campaign on buildings.
}

\author{
J. Toniolo $^{1}$, C.Silvi $^{1}$ and M. Masoero ${ }^{1}$ \\ ${ }^{1}$ Department of Energy, DENERG \\ Politecnico di Torino \\ C.so Duca degli Abruzzi 24, 10129 Torino (Italy) \\ Phone number:+39 0904441-4458-4435, fax number: +300904499, \\ e-mail: jacopo.toniolo@polito.it, chiara.silvi@polito.it, marco.masoero@polito.it
}

\begin{abstract}
The European EPBD (Energy Performance in Buildings Directive) imposes mandatory inspection of HVAC systems with the aim of reducing building energy consumption and $\mathrm{CO}_{2}$ emission. Even if an inspection methodology was developed by HARMONAC IEE project, only few member states include mandatory inspection in national legislation. The methodology was tested on 400 buildings around Europe, showing some general problems on HVAC control. The main issue concerns HVAC system monitoring: without reliable energy consumption data, it is really difficult to achieve the EPBD main aim, the reduction of energy consumption. In this paper some examples are shown, demonstrating the importance of energy monitoring and correct HVAC control set up.
\end{abstract}

\section{Key words}

HVAC, EPBD, continuous monitoring systems, inspection.

\section{Introduction}

Air conditioning systems can account for up to $50 \%$ of the energy used in a building, and have therefore been specifically targeted by energy legislation in the last decades. The Energy Performance of Buildings Directive (EPBD) was published in 2002 (Directive 2002/91/CE), with the aim of reducing $\mathrm{CO}_{2}$ emissions within the building sector. Article 14 of the 2010 EPBD recast requires regular inspection of the accessible parts of airconditioning systems of an effective rated output of more than $12 \mathrm{~kW}$ [1].

While it is evident that a well controlled and maintained HVAC system is more efficient than a poorly controlled and maintained one, it is not proved that Inspection alone can ensure such conditions. There is also a general lack of well established procedures for standardized HVAC system inspections. The result is that so far only a few
Member States (MS) have transferred this prescription into national law.

The paper is focused on some results of project HARMONAC, funded in 2007-2010 by IEE (Intelligent Energy for Europe) [2]. HARMONAC was intended to provide actual energy consumption data on HVAC systems in Europe and to establish standard inspection tools and criteria. Some results from HARMONAC were actually used to recast the EPBD at this actual form (EPBD, Directive 2010/31/EU).

Dome case studies carried out in Italy demonstrated that HVAC inspections, even if developed with a high level of detail, are not sufficient to ensure system efficiency. In addition, the presence of a BMS (Building Management System) is not a sufficient condition to achieve a satisfactory HVAC system efficiency. To reach this result, the BMS needs a correct design and commissioning, a frame dedicated to energy monitoring and a properly instructed operator.

\section{Objective of the work}

The IEE HARMONAC project was developed to reach a number of clear purposes:

1) To produce a series of $A C$ Inspection procedures, to be applied by $M S$ in the framework of EPBD Directive.

2) To provide new field-tested materials and tools to aid Inspectors in the Inspection process.

3) To understand more clearly how Air Conditioning systems consume energy.

4) To assess the opportunities for energy savings.

The project ensured that the information was presented to the main actors, involved in HVAC systems mandatory inspection, in order to help them to produce regulations 
and legislation in this area. In fact, a system owner is supposed to invest a considerable amount of money in such inspections, so that he will be looking forward to achieving some energy and cost benefits in return.

A clear and unexpected result of the project was to get aware of the usefulness of continuous monitoring to HVAC inspectors' work and to reliable benchmarking of HVAC system.

HVAC system inspections require specific competences and portable instruments, and typically last a few days (depending on system/building size): they are therefore expensive and it is not guaranteed that the benefits potentially achieved will last in post-inspection operation (the auditor cannot check what happens after he has completed his work).

On the other hand, a monitoring system that acquires and logs fundamental electrical loads (HVAC, lighting, PCs) represents a relatively small investment that lasts for a long time. It allows to control system performance at the required time scale and to verify the results of applied ECOs (Energy Conservation Opportunities) [3].

Some of the results of Italian case studies concern highend HVAC systems that, based on monitoring results, turned out to be either poorly controlled or managed: that could account up to about $30 \%$ of energy waste [4].

\section{Methodology}

Due to the main focus of the project, all the systems analyzed passed through an accurate HVAC system and building inspection. This inspection was carried out in a standard way for all the Field Trials (FT) and Case Studies (CS) throughout Europe. A FT basically consists of the inspection of the HVAC system, including pre-inspection and on-site inspection, sometimes complemented by shortterm measurements. A CS combines to the inspection a long-term monitoring and analysis of energy saving potentials, based on measurements and/or simulations. The energy consumption of the AC systems and of their components have been monitored in sub-hourly detail, where the CS were monitored for at least one year, while the FT for a short time period (variable between 7 and 90 days). The main idea is that the CS should help to understand the HVAC consumption difference due to seasonal variation and major building / system refurbishment (e.g.: chiller substitution, windows retrofit, etc). On the other hand, the FT were intended to simulate short time on site inspections and to analyze some specific HVAC system aspects (e.g.: control strategy, chiller efficiency, etc). Most of the FT were enhanced by measurements, which go beyond the current inspection requirements, to provide more insights about specific HVAC system aspects.

The CS were carried out, within the project constraints, studying the energy uses and the O\&M (Operation and Maintenance) regime of about 40 systems around Europe, in order to analyze in detail the causes of the energy consumptions and, consequently, to define and quantify the possible ECOs.

Further concern of HARMONAC was directed to the ECOs identification and assessment. The FT and CS are complementary: the Case Studies provide us with detailed information about HVAC systems energy consumption, allowing to identify some more ECOs that could have escaped during the inspection procedure, together with the relative importance of such ECOs in the overall energy balance of the HVAC system; still, the Field Trials are crucial to assess the practice of the inspection procedure on a real system, and to predict the possible ECOs.

Long term CS were conducted for at least one year; data monitored (at 15-60 minutes sampling rate) were intended to understand HVAC consumption with respect to the global electric demand of the building. HVAC system monitoring was carried out by measuring the electric consumption of the following components:

\section{1) Chillers (condenser fans or evaporative towers included) \\ 2) Chilled water pumps \\ 3) AHU fans}

The monitoring schedule was adapted to the HVAC system type (for example, in the case of VRF systems the external units only were monitored). The electric consumption of the building was measured by the fiscal counter (digital meter providing the total consumption at 15 minute intervals) and by other electric meters dedicated to specific loads (lighting, computers, etc...). The electric meters, installed in the electric panel, have an accuracy of $0.5 \%$. In a conservative way, an accuracy of $1 \%$ was assumed in our analyses.

Due to the weather dependence of HVAC consumption, climatic data were acquired for ECOs assessment. These data were validated and provided by the Regional Environmental Protection Agency (ARPA). The building internal room temperature was measured and logged with the temperature sensors of the BMS (large errors in temperatures probes were often detected, around $1-2^{\circ} \mathrm{C}$ ).

For the Field Trials the monitoring tools were provided by POLITO; electric energy monitoring was carried out with portable instruments: DENT ELITE PRO (True RMS measurements, $0.5 \%$ error, 128 sampling per cycle). Room temperature and $\mathrm{RH}$ (relative Humidity) monitoring was carried out with portable loggers: TESTO 175H2 and Comark N2013.

\section{Field Trials and Case Studies for Italy}

Five CS and fourteen FT have been completed in Italy. Most Italian CS were carried out in large office buildings; one CS examined a retirement home. The examined buildings were located in Northern Italy, in the cities of Torino, Genova, and Trieste. The conditioned floor areas of the buildings ranged between 4800 and 
$24000 \mathrm{~m}^{2}$. Different typologies of HVAC systems were analyzed:
1) All air $(C A V)$
2) All air $(V A V)$
3) All water (with fan coils)
4) Air and water (with active chilled beams or fan coils)
5) VRF air to air reversible heat pump

Central heating and cooling production included conventional electric chillers (air cooled or water cooled) coupled with gas-fired boilers, absorption chillers coupled with biomass combustion boilers, tri-generation units with IC engines, and VRF heat pumps.

The building structure typologies were diversified. The Italian CS included: a XVII century masonry building, largely rebuilt in reinforced concrete after WW-II (CS IT5); A high-rise office tower with curtain walls and large glazed surfaces built in 2004 (CS IT-4); A set of three Surgery rooms served by one dedicated HVAC system in a 1970's Hospital (FT IT-3). The present paper will illustrate most representative cases in terms of good or bad programming of BMS. Cases are shown in Tables I and II.

Table I. - Examples of Case Studies

\begin{tabular}{|l|l|l|l|}
\hline Code & CS IT-1 & CS IT-4 & CS IT-5 \\
\hline Location & Torino & Genova & Torino \\
\hline $\begin{array}{l}\text { Main } \\
\text { activity }\end{array}$ & Office & $\begin{array}{l}\text { Open plan } \\
\text { offices }\end{array}$ & $\begin{array}{l}\text { Single room } \\
\text { offices }\end{array}$ \\
\hline $\begin{array}{l}\text { System } \\
\text { Type }\end{array}$ & $\begin{array}{l}\text { all water } \\
\text { system (no } \\
\text { mechanical } \\
\text { ventilation) }\end{array}$ & $\begin{array}{l}\text { Air and } \\
\text { water } \\
\text { (chilled } \\
\text { beams) }\end{array}$ & $\begin{array}{l}\text { VRF with } \\
\text { mechanical } \\
\text { ventilation }\end{array}$ \\
\hline $\begin{array}{l}\text { Year } \\
\text { construction }\end{array}$ & 1970 & 2004 & $\begin{array}{l}\text { 1650-1950 } \\
\text { (Refurbished } \\
\text { in 2004) }\end{array}$ \\
\hline $\begin{array}{l}\text { Net } \\
\text { conditioned } \\
\text { area [m²] }\end{array}$ & 4840 & 8591 & 9500 \\
\hline
\end{tabular}

Table II. - Examples of Field Trials

\begin{tabular}{|l|l|l|l|}
\hline Code & FT IT-1 & FT IT-3 & FT IT-11 \\
\hline Location & Aosta & Ivrea & Pordenone \\
\hline $\begin{array}{l}\text { Main } \\
\text { activity }\end{array}$ & $\begin{array}{l}\text { Single room } \\
\text { offices }\end{array}$ & $\begin{array}{l}\text { Surgery } \\
\text { rooms }\end{array}$ & City council \\
\hline $\begin{array}{l}\text { System } \\
\text { Type }\end{array}$ & $\begin{array}{l}\text { Air and } \\
\text { water } \\
\text { (chilled } \\
\text { beams) }\end{array}$ & $\begin{array}{l}\text { All air } \\
\text { system } \\
\text { (CAV) }\end{array}$ & All water \\
\hline
\end{tabular}

\begin{tabular}{|l|l|l|l|}
\hline $\begin{array}{l}\text { Year of } \\
\text { construction }\end{array}$ & 2004 & 1974 & 1980 \\
\hline $\begin{array}{l}\text { Net } \\
\text { conditioned } \\
\text { area }\left[\mathbf{m}^{2}\right]\end{array}$ & 3500 & 105 & 3400 \\
\hline
\end{tabular}

\section{Monitoring results}

There are some practical limitations to an inspection, due to the strict schedule and the inherent 'snapshot-in-time' nature of the procedure. In this investigation, however, several tools were developed and tested in order to learn how the inspection can be useful for forecasting the energy savings in the actual system, so that the inspection worth will be increased. Nevertheless, without a reliable energy consumption data set it is almost impossible to achieve a reliable ECOs evaluation and the associated ROI (Return of Investment).

As stated in paragraph 3, the inspection results were organized in standard reports, in which the most interesting results are represented by the monitoring data.

Due to the specificity of each HVAC system and building, automated analyses were not possible. All the data passed through a visual check and a comparison with expected building occupancy hours. To manage a large amount of data, organized in a sequential form, carpet plots were used. This representation gives a quick qualitative analysis on how the HVAC system or component hourly operation is related to building occupancy (the interpretation of a carpet plot is given in fig.1).

Main result of our survey was the identification of crucial BMS programming errors or misused HVAC system control. When possible the amounts of energy waste due to such inefficiencies were estimated.

The carpet plot is useful to identify schedule and control problems, but it does not provide quantitative analysis. A confident estimation on energy savings potential related to schedule and control adjustment may be done by applying linear regression techniques to the measured data, which is a necessary step to obtain results normalised for climatic conditions [5]. When possible, the identified schedule / control problems were corrected (following [6]) and the energy savings achieved with such actions were measured. 


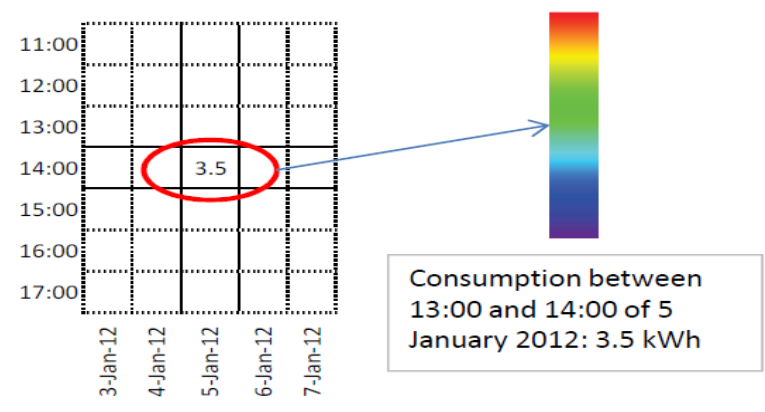

Figure 1: Interpretation of a carpet plot

Figure 2 shows the consumption of a VRF module serving a portion of an office building: the monitored external unit serves about 10 internal units, each one in a different single office. Even if the BMS is particularly complex and complete, the monitoring part lacks reliability: white lines, in fact, represent missing data. In addition, during winter season the system is always on, even if the building has a standard 9 hours per day, 5 days per week occupation.
In Figure 3 two of such modular systems are represented: MC5 shows a unit that was monitored as it was, without any change in the BMS setting: as seen, the unit is turned on 24 hours, 7 days per week. On MC3 the BMS was reprogrammed with a correct schedule, which was adjusted with different pre-cooling hours, depending on the day of the week. At lunch time all the internal units are shut off for one hour, while the occupants are able to turn on the internal unit on request (that's why the off time is not constant). At 16:00 all the internal units are set to off: again the occupants could turn the units on, but each hour the BMS sends the off command again. In this way offtime running of the VRF unit was completely avoided.

Energy savings due to BMS reprogramming accounts to about $35 \%$ of VRF consumption. This value is limited due to the high thermal mass of the considered building. In lighter building it could increase to about $50 \%$.
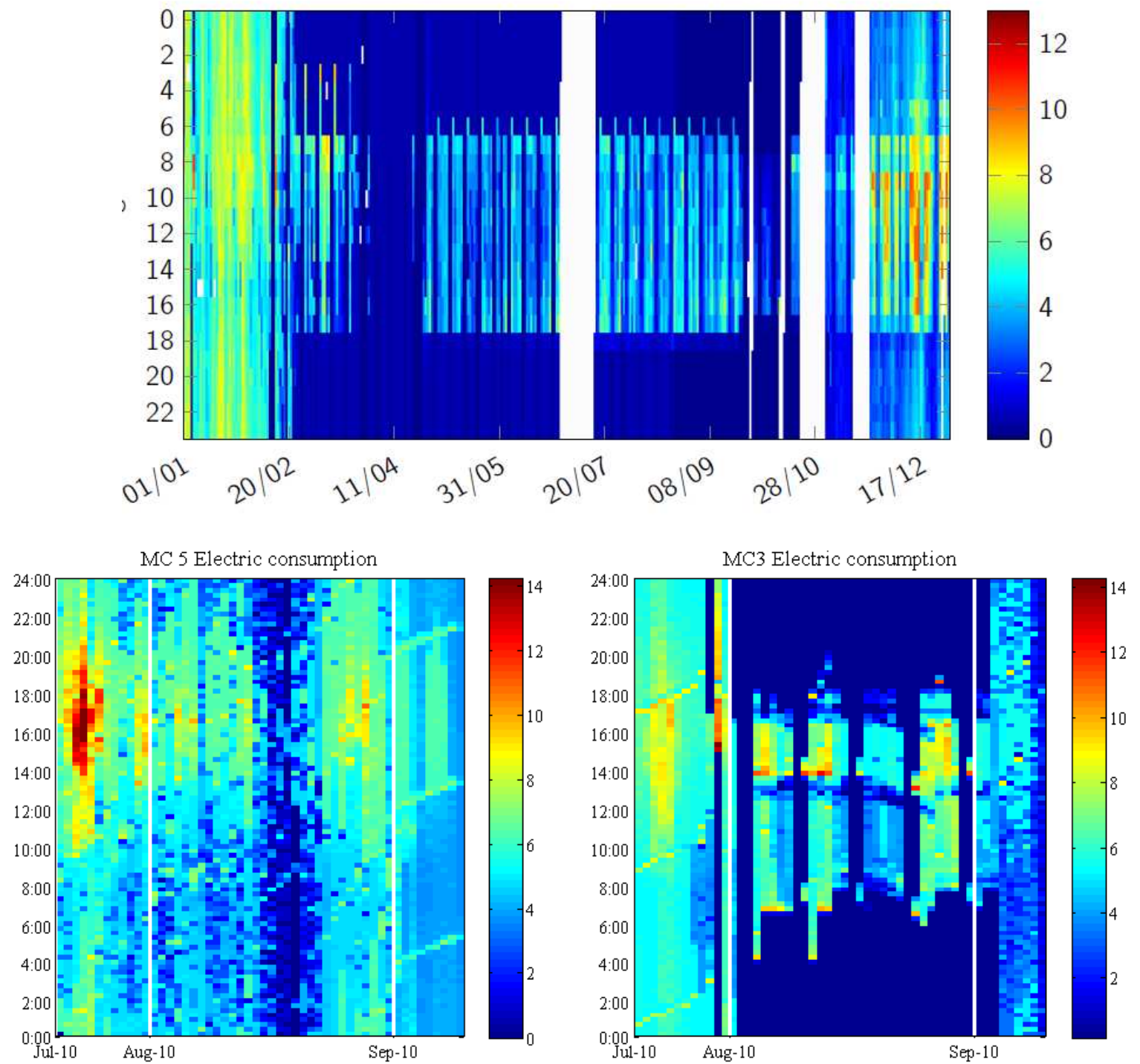

Figure 3: IT CS-5, Schedule adjusting and BMS reprogrammed, difference on the same type of VRF unit 
Some HVAC systems did not show any problem during their physical inspection. This is the case of IT FT-1: the system was quite new and well maintained, while the BMS showed correct occupancy/non occupancy schedules. After a short term energy monitoring of the water condensed chiller serving the building, the conclusion was different. Figure 4 shows the daily energy consumption of the chiller. As seen, the consumption during working days and weekend days is quite similar, while in the latter case it should be equal or close to zero. In effect the BMS was not functioning as we imagined from its setup. Almost all of such problems would have been completely neglected if the inspection only was carried out: monitoring was therefore crucial to obtain a realistic evaluation of the system performance.

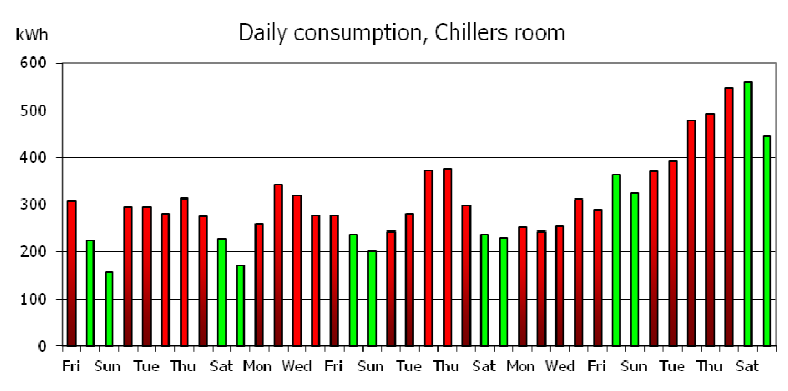

Figure 4: IT FT-1, Chiller consumption in office building

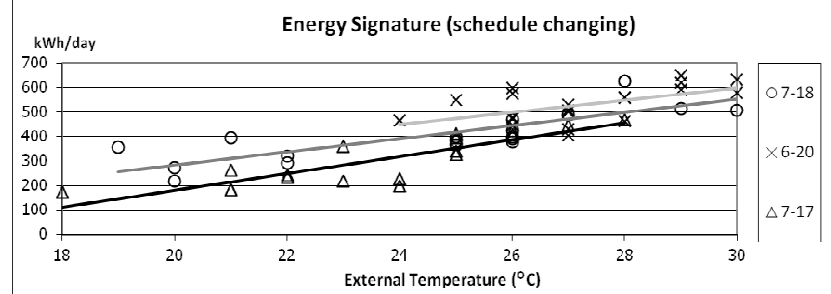

Figure 5: FT IT-11, decrease in chiller consumption according to the schedule modification

The scatter plot in Figure 5 shows the daily consumption of a water condensed chiller (using well water) during the summer season (FT IT-11) as a function of the daily mean temperature. The schedule was changed along the season, taking into account the occupants feelings about internal comfort. The chiller daily operation time was reduced from 14 hours (6:00 AM-8:00 PM) to 11 hours (7:00 AM$18 \mathrm{PM}$ ) and finally to 10 hours (7:00 AM-17:00). The regression analysis on the above data indicates a mean reduction of chiller energy consumption on the order of 5$6 \%$ for each hour in which the chiller is shut off.

\section{Inspection and Monitoring cost comparison}

The cost for inspection can be estimated taking into account the hourly rate a of skilled engineers plus the cost of specific instruments. Based on HARMONAC results, the time to accomplish a complete inspection, composed by pre-inspection (document collection and examination) and physical on-site inspection, can be estimated with the following regression equations:

$$
\begin{aligned}
& T p=4255.3 \cdot G I A^{-0.827} \\
& T i=20242 \cdot G I A^{-0.911}
\end{aligned}
$$

where $G I A=$ Building Gross Internal Area $\left(\mathrm{m}^{2}\right)$

$T p=$ time for pre-inspection

$T i=$ time for Physical Inspection

This leads to about two 8 hours full days of work to inspect a $3000 \mathrm{~m}^{2}$ building. An additional day is needed to prepare the report [2]. This means about 24 hours of work at $60 € / \mathrm{h}$. The cost of equipment for two days is about $500 €$, which leads to the total inspection cost: $500+(60 * 24)=1940 €$.

If energy monitoring is required and the BMS is not equipped with such capabilities, ad hoc instrumentation must be provided. Meters installed in the electric panel have different prices, depending on the presence of Current Transformers (CT). Generally, for currents up to $40 \mathrm{~A}$, direct insertion units are used. These units cost less than $100 €$, but the installation requires a modification of the electrical panel and a new certification, with related fixed costs (about $400 €$ ). It is obvious that if several meters are installed in a single panel, the installation and certification cost per unit could be lowered. When the currents exceed $40 \mathrm{~A}, \mathrm{CT}$ are needed ( 2 for 1-phase loads and 3 for 3 -phase loads). Unit cost for CT is about 50$100 €$. Power meters that work with CT cost around $250 €$.

In addition a main unit is necessary, collecting all the meters data and sending them by a LAN or UMTS connection. The latter one is often preferred by end users, especially in strict secure networks (as those of banks), because it does not interfere with company network. This unit often integrates also a power meter. The cost is about $600 €$.

So, for a medium building $\left(3000 \mathrm{~m}^{2}\right)$, with five loads (three 3-phase and two 1-phase) monitored, it is possible to estimate the following costs:

1. main unit with integrated power meter: $600 €$

2. 2 Power meters: $500 €$

3. 9 CT: $900 €$

4. 2 direct insertion Power meters: $200 €$

5. Installation: $1000 €$

Total metering cost: $3200 €$

From the above data, it clearly appears that the cost for inspection is about two thirds of the cost for power meters installation. However, as explained in the previous examples, one should be aware of the limitations implied by the inspection procedure, limitations that can be overcome if permanent energy monitoring is provided either by the existing BMS or by dedicated instrumentation installed. 


\section{Conclusions}

The main conclusion we support after this 3 year project is that HVAC inspection alone will not affect HVAC system efficiency, and consequently it will not help to reach the 202020 energy reduction target proposed by European Union. This is due to a number of reasons, namely:

1) Temporary and partial focus: An HVAC system passed through a valid Commissioning is supposed to work to its best performance, in terms of comfort and energy efficiency. But how long will this condition last? One month? One year? Neither commissioning, nor inspection could ensure, guarantee or correct HVAC operation for the future, because there is no possibility to have feedback after the physical check. In addition, the physical check is seldom sufficient to have a global knowledge on how the HVAC system is working, especially during the non occupation periods (e.g. IT FT-1, as described in chapter 5).

2) Market perception: To explain this problem we take into account what happened in Italy with the Energy Performance Certificates of buildings (EPC). The EPC led to a change in new constructions, but did not affect sensibly the actual building market. In addition, some distortion exists in mandatory EPC market. The imposition of EPC is somehow felt as a tax instead of a relatively complex calculation, made by a (theoretically) trained auditor. This leads to a cheap certification market, where the end user is not really concerned about the quality of the work, but just on the existence of the document. Our concern is that mandatory inspections, imposed by MS, without other alternatives (comparison with benchmarks or average consumption, etc...), will be evaluated by the market in the same way, i.e. as a bureaucratic imposition. The solution to improve HVAC inspection legislation is to consider energy monitoring, as stated in Directive 2010/31/EU. We think that energy monitoring standardization could decrease the energy consumptions, and consequently the $\mathrm{CO}_{2}$ emission [7].

In conclusion, the most remarkable achievements of energy monitoring will be the followings:

1) Avoid needless inspection: this is the case of a well controlled and maintained HVAC system, showing good results in terms of monitored energy consumption. This will increase the market perception of inspection as something necessary in the case that HVAC system is running in a poor way. The difficult side of this approach is that a complete set of consumption benchmarks has to be provided to end users. Such values need to be normalized on the basis of a set of main variables (climatic conditions, occupation type and schedule, size of the conditioned zone). To be meaningful the values need to be calculated from a statistically representative sample of buildings.

2) Ensure performance for long time: a monitoring system that logs fundamental electrical loads (HVAC, lighting, PCs) represents a small investment that last for a long time. It permits to control on a daily basis systems performance and to verify results of applied ECOs.

It is quite usual, in Italy, to refurbish the HVAC system when it ends its operational life. With continuous technological improvement, it may happen that the economical break even time to install a new component is shorter than the operational life expectancy of the old one, but such an economical analysis is not possible unless monitoring data are available.

On the other hand, often deep refurbishments or new installations of HVAC systems do not take into account the energy monitoring aspects. Even if designers and building managers have high expectations on full automated BMS, not enough attention to the energy monitoring aspect is paid when the BMS characteristics are specified. Italian CS show that the only way identify major BMS errors, which happen even in new systems, is the logged data analysis.

The result is often that high amounts of energy are lost due to a late substitution of inefficient components / systems, or to a not well controlled new system.

\section{Acknowledgement}

The authors wish to acknowledge the contributions from the other Partners in the HARMONAC project, as well as the financial support provided by the European Commission's Intelligent Energy Europe funding programme.

\section{References}

[1] Directive 2010/31/EU of the European Parliament and of the Council of 19 May 2010 on the energy performance of buildings. Official Journal L 153, 18/06/2010.

[2] Knight I. et al., "HARMONAC Final Report", Can be downloaded at www.harmonac.info.

[3] Masoero, M. and Silvi, C. A proposal for an energy conservation opportunities (ECO) list in auditing of air conditioning systems. Proc. Climamed 2007. Genova, 5-7 settembre 2007, pp. 897-912.

[4] Masoero M., Silvi C. and Toniolo J., Energy performance assessment of HVAC systems by inspection and monitoring. Proc.: CLIMA 2010: Antalya Turkey, REHVA, May (2010)

[5] ASHRAE. 2009 Handbook of Fundamentals, Chapter 19 Energy Estimating and Modeling Methods, Atlanta.

[6] Masoero M. and Silvi C. 2006. AUDITAC Technical Guides for owner / manager of an air conditioning system: Vol. 12 - Building Energy Management Systems control strategies for air conditioning efficiency. http://www.energyagency.at/projekte/auditac.htm.

[7] Jagerman, L and Olson, D. 2007. The EPBD and Continuous Commissioning. Final report of WP2 of Building EQ project. Can be downloaded at http://www.buildingeq-online.net 